\title{
FATORES SOCIOAMBIENTAIS INFLUENCIADOS PELA SECA NA CONSERVAÇÃO DA CAATINGA
}

\author{
M. A. M. SILVA ${ }^{1 *}$, M. N. M. A. FRUTUOSO ${ }^{1}$, S. S. F. B. RODRIGUES ${ }^{1}$ e R. J. M. C. NOGUEIRA ${ }^{2}$ \\ ${ }^{1}$ Instituto Federal de Educação, Ciência e Tecnologia de Pernambuco \\ ${ }^{2}$ Universidade Federal Rural de Pernambuco \\ marcelomauricio@gmail.com*
}

Artigo submetido em fevereiro/2016 e aceito em julho/2016

DOI: $10.15628 /$ holos.2016.4175

\section{RESUMO}

A caatinga ocupa a maior parte da região semiárida do Brasil, encontrada exclusivamente no território brasileiro e por sua extensão está entre as mais importantes florestas secas do mundo. As estiagens recorrentes e os anos de degradação ambiental tornaram a região pouco desenvolvida e com problemas socioeconômicos acentuados. $O$ objetivo do presente trabalho foi apresentar uma síntese socioeconômica e política sobre a seca do semiárido nordestino enfatizando o bioma da região. Para tanto foram considerados critérios relacionados à conservação da caatinga e a educação contextualizada, aliados à convivência com o semiárido, fatores necessários para promoção de mudanças substanciais na estrutura social. A metodologia adotada foi uma análise bibliográfica sobre a seca e a conservação do bioma em questão com foco para a educação e o desenvolvimento sustentável. Identificou-se a necessidade de incentivos à agricultura e melhoria dos indicadores sociais, para um aproveitamento maior de parte do potencial produtivo da região semiárida brasileira.

PALAVRAS-CHAVE: estiagens, semiárido, educação, convivência, desenvolvimento sustentável.

\section{TITULO EM INGLÊS}

\section{ABSTRACT}

The caatinga covers most of Brazil's semi-arid region, found exclusively in the Brazilian territory and by its extension is among the most important the world's dry forests. Recurrent droughts and the years of environmental degradation have made the region underdeveloped and with socioeconomic problems accented. The purpose of this study was to present a socioeconomic and political synthesis about the dry Northeastern semi-arid biome in the region emphasizing. For both were considered criteria related to the conservation of the caatinga and contextualized education, allied to coexistence with the semi-arid, necessary factors to promote substantial changes in social structure. The adopted methodology was a bibliographical analysis on drought and conservation of biome in a matter with focus for education and sustainable development. Identified the need for incentives for agriculture and improvement of social indicators, for a greater use of the productive potential of the Brazilian semi-arid region.

KEYWORDS: droughts, semi-arid, education, coexistence, sustainable development. 


\section{INTRODUÇÃO}

O Nordeste do Brasil é formado por quatro regiões bem específicas: Meio Norte, Sertão, Agreste e Zona da Mata. Também apresenta um espaço geográfico único, constituído pelo Semiárido que estende-se por oito dos nove Estados presentes na região, entre eles: Rio Grande do Norte, Ceará, Bahia, Pernambuco, Paraíba, Alagoas, Sergipe e Piauí (BRASILEIRO, 2009; BRASIL, 2011; IPEA, 2013).

Para Gaspar (2010) e Pereira (2013) a região Nordeste é constituída de pessoas fortes, resistentes e lutadoras formando um rico mosaico de potencialidades. Prova substancial foram os registros da Feira na Cidade de Caruaru como Patrimônio Cultural Imaterial do Brasil em 2006 e também o Frevo de Recife em 2007, pelo Instituto do Patrimônio Histórico e Artístico Nacional IPHAN. Mas, o semiárido ainda permanece carente de políticas públicas voltadas ao desenvolvimento justo, devido à falta de uma gestão adequada dos recursos hídricos somada a períodos constantes de escassez das chuvas.

O semiárido brasileiro, encontrado na região Nordeste é, portanto, uma extensão que apresenta períodos chuvosos curtos e longos meses de estiagem, apresentando uma vegetação diferenciada das demais regiões do Brasil, a caatinga, que exibe grande variedade de formações, adaptada às mudanças climáticas, ou seja, presença ou ausência de água e as condições do solo (REBOLÇAS, 1997; FIGUEIREDO, 2012; SCHACHT, 2015).

Ab'Sáber (2003) afirma que o Nordeste é uma região de clima semiárido, muito quente e sazonalmente seco, com variações no ciclo das águas, no ecossistema das caatingas e no mundo socioeconômico dos sertanejos. Apresentando prolongados períodos de carência hídrica, solos problemáticos tanto do ponto de vista físico quanto geoquímico e parcialidade salina ou carbonática.

Portanto, a falta de água do Nordeste brasileiro reflete a condição de uma região pouco desenvolvida e com problemas socioeconômicos acentuados, conhecidos desde o período da colonização. Mas a região exibe problemas ambientais contemporâneos, também por causa da limitação hídrica, caracterizada pela ausência e escassez das chuvas, que torna a vida dos sertanejos difícil e determina mudanças adaptativas na biota da região (LEAL et al., 2005; SILVA, 2007; BILAR et al., 2016).

Desse modo a seca assinala uma situação climática diferenciada, em uma região que normalmente apresenta chuvas irregulares, aplicando-se completamente ao semiárido brasileiro que apresenta histórico de baixa pluviosidade, ou seja, inerente à região, tornando ilusório o combate ao clima nordestino (SCHISTEK, 2013).

Porém para Baptista e Campos (2013) e Rebouças (2015) o acesso à água é um direito fundamental que precisa ser garantido. Para tanto são necessárias ações que promovam condições de se captar a água em períodos de chuva e utilizá-la em tempos de maiores necessidades, estimulando políticas de convivência com o semiárido. Nesse contexto a importância da água armazenada subdivide-se em quatro perspectivas: primeira água - utilizada para beber e cozinhar, segunda água - utilizada na produção, terceira água - utilizada para comunidade, e quarta água utilizada em períodos de emergência. 
Rêgo (2012) e Rodrigues (2016) afirmam que a falta de água não é o problema do semiárido. Pois, as chuvas na caatinga concentram-se em três meses consecutivos. Portanto, a dificuldade está na distribuição inadequada e insuficiente da água durante os meses de escassez hídrica, o que contribui para agravar outros problemas, como a desertificação, e torna ainda mais instável o equilíbrio ecológico da região devido aos períodos de seca recorrentes que afetam a vegetação.

Diante do exposto o objetivo do presente trabalho foi apresentar uma síntese socioeconômica e política sobre a seca da região semiárida nordestina considerando os impactos sobre a conservação da caatinga.

\section{REVISÃO BIBLIOGRÁFICA}

A caatinga é um bioma exclusivamente brasileiro, mas não apenas nordestino por apresentar uma parcela no Estado de Minas Gerais. É um ecossistema frágil, porém rico em biodiversidade e endemismo. A sua vegetação é diversificada de tal forma que os pesquisadores atuais preferem utilizar o plural, ao invés de caatinga, caatingas, a exemplo do que ocorre com sertão/sertões (RÊGO, 2012; FIGUEIREDO, 2012; DE OLIVEIRA et al. 2015).

A caatinga devido a sua extensa área marcada pelo clima tropical semiárido é considerada uma exceção climática destacando-se como um importante laboratório para estudos de plantas, invertebrados e vertebrados que convivem e expressam adaptações a um regime de chuvas altamente variável e estressante (LEAL et al., 2005; SOUZA et al., 2015).

Consequentemente, deve-se considerar a potencialidade da região semiárida através da sua fisiologia específica, como uma área produtora de riquezas, administrando o uso racional da pouca água disponível, a utilização de lavouras e animais adequados ao clima seco, e promovendo o uso sustentável dos recursos naturais (VASCONCELOS, 2013).

Por ser encontrada exclusivamente no território brasileiro e por sua extensão a caatinga está entre as mais importantes florestas secas do mundo, contudo, recebe pouca atenção dos pesquisadores e governantes brasileiros por está localizada em áreas subdesenvolvidas e por seus produtos apresentarem valores essencialmente locais, como a lenha e o carvão (RIEGELHAUPT et al., 2010).

Em adição Albuquerque et al. (2012) e Araújo (2015) afirmam que mais estudos são necessários para identificação de comunidades e populações de fauna e flora da caatinga, considerando a capacidade de adaptação e a sobrevivência em condições extremas devido a variedade de habitats existentes no bioma, com destaque para as espécies cactáceas, arbóreas, herbáceas e arbustivas.

Cerca de 27 milhões de pessoas vivem na região Nordeste que apresenta um Índice de Desenvolvimento Humano (IDH) baixo o que torna a maioria dos moradores carentes e dependentes dos recursos vegetais da caatinga para sobreviver. Entretanto, o uso dos recursos da caatinga ao longo de centenas de anos de ocupação associado ao desmatamento, a pobreza e a seca acentuam a sensibilidade do bioma (BRASIL, 2011).

A questão do desmatamento é uma ameaça a preservação e a conservação de espécies vegetais e consequentemente animais, e de acordo com Riegelhaupt et al. (2010) noventa e quatro por cento $(94 \%)$ da lenha e do carvão utilizados no bioma caatinga provêm atualmente de 
desmatamento, autorizado ou não, porém essa demanda de produtos madeireiros é de extrema importância para economia da região.

A lenha é consumida intensamente em importantes ramos industriais, como também em domicílios, principalmente na zona rural e a biodiversidade da caatinga fornece uma série de produtos florestais não madeireiros para consumo e comercialização, como frutas, plantas medicinais, cascas, óleos, mel, material para artesanato, raízes comestíveis, entre outros produtos (BRASIL, 2008).

Infelizmente a degradação ambiental ocorre desde muitos anos devido ao pouco conhecimento das famílias sertanejas que fizeram uso de queimadas destruindo extensas áreas de caatingas para produção de carvão vegetal e utilizaram irrigação pesada em solos rasos causando salinização e lixiviação da matéria orgânica (VASCONCELOS, 2013; DE SOUZA \& DO NASCIMENTO, 2015).

Nesse contexto é interessante considerar a sustentabilidade, fator preponderante para o desenvolvimento do país com uso racional dos recursos naturais. Portanto se faz necessário que o processo de crescimento aconteça com a preservação da capacidade produtiva desses recursos em nível regional para que resultados positivos se reflitam nacionalmente (CIRILO, 2008; AMPARO, 2014). Pois, não é mais aceita, pela sociedade, a exploração indiscriminada dos recursos naturais que comprometa o planeta prejudicando as gerações futuras, exigindo dessa forma padrões diferentes de consumo, como também a racionalidade no uso dos recursos naturais, especialmente água e fontes geradoras de energia, assim como no destino final dos resíduos (BRASIL. Secretaria de Desenvolvimento Regional, 2012).

Outro problema da região Nordeste é o acesso insuficiente a terra por boa parte da população devido ao modelo econômico adotado quando da época de colonização com excessiva exploração dos recursos naturais e ausência dos estudos de ecologia, bem como a falta de políticas centradas na perspectiva da convivência com a seca (BAPTISTA \& CAMPOS, 2013).

Igualmente a concentração fundiária do Nordeste semiárido demonstra o atraso das formas históricas de ocupação dos espaços e dos recursos gerando desigualdade socioeconômica, e as políticas públicas destinadas à região semiárida não reverteram o processo de concentração, fato que influencia diretamente a situação de miséria nos períodos prolongados de seca (SILVA, 2003; GONÇALVES \& DE ARAÚJO, 2015).

Assim, formas de gerenciamento ambientalmente adequadas e mais recentes voltadas à sustentabilidade e aliadas ao acesso aos bens sociais, como terras férteis e água, são imprescindíveis para o uso adequado desses recursos naturais, no Semiárido, considerando uma potencialidade crescente, ao decorrer do tempo, do desenvolvimento socioeconômico (CIRILO, 2008; DE AZEVEDO, 2012).

De acordo com Pereira (2013) é interessante considerar a Educação Contextualizada como elemento fundamental para a construção de um projeto de desenvolvimento sustentável no semiárido brasileiro, buscando valorizar a região e as pessoas com a elaboração de políticas públicas adequadas que possibilitem uma educação que contemple a realidade.

A Educação Contextualizada no Semiárido apresenta como um de seus fundamentos o artigo 1 으 da Lei de Diretrizes e Bases da Educação Nacional - LDB (9.394/96) onde os temas 
ambientais passaram a ser considerados como transversais nos Parâmetros Curriculares Nacionais (PCN's) do Ensino Fundamental (BRASIL, 1996; ARAÚJO \& SOUSA, 2011).

Segundo os PCN's torna-se extremamente importante essa transversalidade de temas, pois são linhas do conhecimento que atravessam o tempo e se cruzam entre diferentes disciplinas, atuando como fator estruturador e fio condutor da aprendizagem, potencializando valores que respondem às necessidades pessoais e da própria sociedade (BRASIL, 1998; MARINHO et al., 2015).

Deste modo a educação passou a ser abordada para além da escola, permitindo que as Organizações Não-Governamentais - ONG's fossem reconhecidas como espaços educativos/formativos que desencadeiam novos modos de intervenção social, sendo considerada a Educação Contextualizada como fruto de uma destas experiências que teve como princípio inovador o desenvolvimento regional traduzido em convivência com o semiárido (SOUZA, 2010).

Nessa conjuntura a convivência com o semiárido é apropriada para identificar as realidades dos ecossistemas e a valorização de conhecimentos, valores e práticas relacionadas ao ambiente local articulando iniciativas que visem à melhoria da qualidade de vida das populações, compreendendo os fenômenos climáticos e geofísicos como uma condição natural recorrente (SILVA, 2003; FALCÃO \& FALCÃO, 2008).

O modelo de Educação Contextualizada valida os saberes e experiências locais reconstruindo conceitos de conhecimentos focados em experiências de vida, reconhecendo a necessidade e a importância das especificidades locais no desenvolvimento do trabalho educativo no semiárido, propondo criar formas sustentáveis apropriadas aos fenômenos naturais com a destituição da expressão combate à seca (SOUZA, 2010; SANTOS et al., 2011).

Portanto a prática educacional aliada à convivência com o semiárido apresenta o enriquecimento necessário para promoção de mudanças substanciais na estrutura social, integrando a identidade local comunitária com a utilização sustentável dos bens naturais em um processo denominado de aprendizagem social (FALCÃO \& FALCÃO, 2008; LUCENA, 2015).

Essa aprendizagem também está diretamente relacionada à educação ambiental que aborda a preservação da fauna e flora do semiárido, o cuidado com as reservas de água, e, a adubação natural da terra a ser cultivada, na tentativa de restaurar a biodiversidade e combater a desertificação apresentando propostas de convivência adequadas ao ambiente local (BAPTISTA \& CAMPOS, 2013).

\section{METODOLOGIA}

A metodologia adotada foi uma revisão sintética sobre a seca e a conservação da caatinga, com enfoque para a educação e o desenvolvimento sustentável, através da análise bibliográfica de fontes científicas atuais, discutindo a importância desses temas na atualidade. Também foi utilizado o Atlas do Desenvolvimento Humano no Brasil com dados de 2010, para a realização de classificações do Índice de Desenvolvimento Humano Municipal (IDHM) tanto dos municípios brasileiros quanto especificamente da região semiárida, considerando os municípios presentes nos Estados do Rio Grande do Norte, Ceará, Bahia, Pernambuco, Paraíba, Alagoas, Sergipe e Piauí. 


\section{RESULTADOS E DISCUSSÕES}

Para que ocorra melhoria das condições de vida no semiárido brasileiro é necessário uma profunda mudança socioeconômica e política enraizada no desenvolvimento sustentável com vistas para a preservação do bioma caatinga. Portanto deve-se considerar a união dos caracteres observados no esquema abaixo na Figura 1, em um contexto no qual fatores climáticos e sóciohistóricos devem ser valorizados.

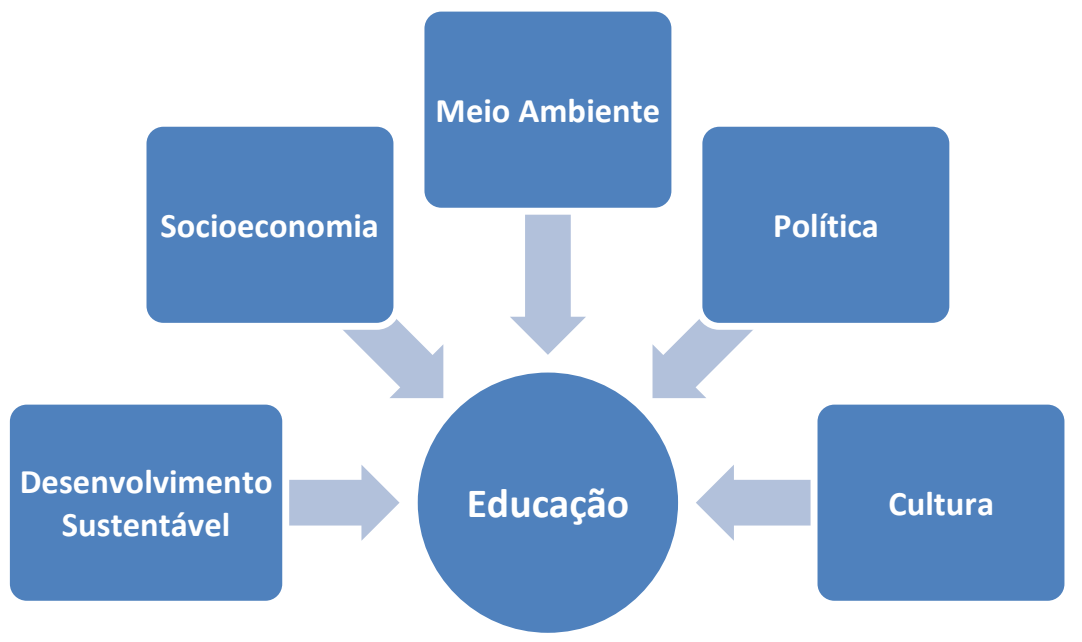

Figura 1: Fatores climáticos e sócio-históricos envolvidos na proposta de melhoria das condições de vida do semiárido brasileiro. Fonte: Autores, 2016.

Para Durkheim (2011) e Halal (2015) o homem, mais do que formador da sociedade, é um produto dela, dessa forma, a educação beneficia a sociedade e quanto mais eficiente for o processo educativo, melhor será o desenvolvimento da comunidade em que a escola esteja inserida.

Segundo Freire (2008) educação é a constante busca do conhecimento realizada por um sujeito que é o homem, apresentando caráter permanente, e, portanto o conhecimento só tem sentido quando situado no contexto.

Nessa conjuntura a convivência com o semiárido só pode ocorrer de forma efetiva com educação de forma contextualizada, e ações pontuais de combate à seca não solucionam a problemática social. Dessa forma é essencial à compreensão da realidade local para construção de ações favoráveis as mudanças eficazes.

Leal et al. (2005) e Félix et al. (2012) alertam para a conservação regional da caatinga ressaltando o controle da desertificação, a manutenção de serviços necessários para a qualidade de vida da população, e a utilização sustentável dos recursos naturais da região para promoção de um desenvolvimento econômico que produza trabalho e renda para as famílias por meio de alternativas sustentáveis.

Nesse contexto é coerente afirmar que a caatinga apresenta imenso potencial para a conservação de serviços ambientais e uso sustentável que, se bem explorada, pode ser decisiva para o desenvolvimento da região Nordeste e do país. E a biodiversidade da caatinga ampara diversas atividades econômicas voltadas para fins agropastoris e industriais, destacando a importância de sua preservação. 
Segundo Rebouças (1997) e Rebouças (2015) o desenvolvimento sustentável deve está aliado ao crescimento econômico, à conservação ambiental, a qualidade de vida e o equilíbrio social, considerando a seca um fator social, além de sua marca física. Assim a sustentabilidade no semiárido está intimamente relacionada a uma convivência harmoniosa do sertanejo com o seu meio ambiente.

Entretanto, a região Nordeste cresce economicamente a duros custos, apresentando baixos índices sociais e a permanência da concentração de renda pela minoria da população em comparação às demais regiões brasileiras, situação agravada em períodos de limitação hídrica reforçando a crise de produção na agricultura como também a miséria.

Para Ab'Sáber (1999) a região Nordeste brasileira é carente de projetos e incentivos econômicos duradouros. As ações existentes apresentam alcance desigual, com programas incompletos e desintegrados de desenvolvimento regional, são atualmente pontuais resolvendo a questão da seca de forma temporária, sendo extremamente importante a criação de práticas e métodos produtivos que se adequem as necessidades locais e regionais.

Isto se retrata em um quadro atual, onde, devido ao período de estiagem e seca, oito Estados do Nordeste passaram por situação de emergência em 2012, com a população afetada superior a nove milhões de pessoas distribuídas em 1.126 municípios nos Estados de Alagoas, Bahia, Ceará, Paraíba, Pernambuco, Piauí, Rio Grande do Norte, e Sergipe (BRASIL, 2012).

Em contrapartida o Governo Federal na tentativa de minimizar os efeitos da estiagem prolongada criou a bolsa estiagem ou auxílio emergencial instituído pela Lei № 10.954 de 2004, sendo um benefício financeiro para assistência dos agricultores familiares nordestinos em situação de emergência ou calamidade pública reconhecida pelo Governo Federal a partir de 2012 (BRASIL, 2013).

Portanto, é comum a pratica de ações pontuais decorrentes da falta e/ou deficiência de políticas frequentes relacionadas às condições de convívio com a seca no semiárido. Quando na realidade, o que existe é a má distribuição e aproveitamento dos recursos hídricos no curto período de chuvas e algumas práticas ineficientes de utilização do solo e da vegetação que se comprovam nos dados negativos do Atlas do Desenvolvimento Humano no Brasil de 2010 que trata do Índice de Desenvolvimento Humano Municipal (IDHM).

O Atlas do Desenvolvimento Humano no Brasil de 2010 revela que 90,46\% dos municípios do semiárido brasileiro apresentam baixo Índice de Desenvolvimento Humano Municipal (IDHM) entre 0,500 a 0,650 conforme Tabela 1, e segundo o Ipea (2013) estima-se que 59\% da população do semiárido viva sem as condições necessárias de dignidade relacionadas aos indicadores de renda, educação e longevidade. Corroboram com esse resultado os dados apresentados por Silva (2007) que realizou estudos sobre o semiárido brasileiro considerando as informações obtidas no Atlas de Desenvolvimento Humano no Brasil, utilizando dados do ano de 2000.

Portanto não houve mudanças notórias relacionadas à melhoria de vida do sertanejo entre 2000 a 2010, e os percentuais obtidos permanecem superiores a média nacional, que possui $44,06 \%$ dos municípios nessa mesma faixa conforme Tabela 2. Conforme observado no trabalho de Silva (2007) nenhum município do semiárido está na faixa mais elevada do IDHM de 2010 (entre 0,801 a 1,000), com aumento no número de municípios na faixa entre 0,501 a 0,650 e diminuição entre 0,651 a 0,800 tanto para os valores do Brasil quanto do semiárido. 
O Índice de Desenvolvimento Humano Municipal considera os indicadores sociais como: saúde, educação e renda com ênfase para os 5.565 municípios brasileiros, revelando a estagnação da região Nordeste em comparação com as demais regiões brasileiras e demostrando a persistência das desigualdades sociais. E ainda conforme dados observados no Atlas do Desenvolvimento Humano no Brasil de 2010, a concentração de renda permanece maior na região Sudeste do Brasil, influenciando outros parâmetros como a educação.

Entretanto, os menores valores observados em relação aos cinquenta últimos municípios encontrados no Atlas do Desenvolvimento Humano no Brasil de 2010 revelam que vinte três estão na região Nordeste do Brasil, nos Estados de Piauí, Pernambuco, Alagoas, Bahia e Maranhão, e os demais vinte sete municípios localizam-se nos Estados de Pará, Amazonas, Roraima e Acre, ou seja, região Norte do Brasil. Assim, são extremamente importantes ações socioeconômicas direcionadas não apenas a região Nordeste e consequentemente ao semiárido brasileiro, mas também as demais, visto que o Brasil por sua extensão geográfica apresenta muitas realidades.

Tabela 1: Índice de Desenvolvimento Humano e Educacional - Atlas Brasil (2010). Fonte: Autores, 2016.

\begin{tabular}{ccccc}
\hline & \multicolumn{5}{c}{ Semiárido Brasileiro } \\
\cline { 2 - 5 } IDHM 2010 & Municípios & Educação & No \\
Até 0,500 & 10 & 0,64 & 941 & 59,8 \\
0,501 a 0,650 & 1434 & 91,1 & 611 & 38,8 \\
0,651 a 0,800 & 130 & 8,26 & 22 & 1,4 \\
0,801 a 1,000 & 0 & 0 & 0 & 0 \\
\hline Total & 1574 & 100 & 1574 & 100 \\
\hline
\end{tabular}

Tabela 2: Índice de Desenvolvimento Humano e Educacional - Atlas Brasil (2010). Fonte: Autores, 2016.

\begin{tabular}{|c|c|c|c|c|}
\hline \multirow{3}{*}{ IDHM 2010} & \multicolumn{4}{|c|}{ Brasil } \\
\hline & \multicolumn{2}{|c|}{ Municípios } & \multicolumn{2}{|c|}{ Educação } \\
\hline & № & $\%$ & № & $\%$ \\
\hline Até 0,500 & 35 & 0,63 & 1582 & 28,43 \\
\hline 0,501 a 0,650 & 2417 & 43,43 & 2963 & 53,24 \\
\hline 0,651 a 0,800 & 3073 & 55,22 & 1015 & 18,24 \\
\hline 0,801 a 1,000 & 40 & 0,72 & 5 & 0,09 \\
\hline Total & 5565 & 100 & 5565 & 100 \\
\hline
\end{tabular}

A região Nordeste do Brasil concentra $28 \%$ da população brasileira, entretanto responde por apenas $13 \%$ do PIB, o que corresponde a menos da metade da média nacional e em comparação com o Estado de São Paulo é quatro vezes menor. Como consequência, o Nordeste concentra $53 \%$ dos analfabetos e $59,1 \%$ da população extremamente pobre do país (BRASIL. Secretaria de Desenvolvimento Regional, 2012).

O Atlas do Desenvolvimento Humano no Brasil de 2010 corrobora com as informações citadas revelando que $98,6 \%$ dos municípios do semiárido brasileiro apresentam baixo Índice Educacional entre 0,500 a 0,650, entretanto, esse valor não está distante da taxa nacional que é de $81,67 \%$ em comparação com a mesma faixa. Revelando que o Brasil apresenta um grande desafio na busca por melhorias educacionais e manutenção da qualidade de ensino. 
Porém, devido às ações sociais e econômicas promovidas pelo governo, como: aumento do salário mínimo, aposentadoria rural, maior apoio a agricultura familiar e empregos gerados por grandes obras de infraestrutura ocorreu um aumento do consumo das famílias nas regiões menos favorecidas. Resultando na queda do índice de GINI, instrumento utilizado para medir a desigualdade social em determinado grupo e que aponta a diferença entre os rendimentos dos mais pobres e dos mais ricos, de 0,59 para 0,54, contudo, o grande desafio nacional atual está em manter a estabilidade dos desenvolvimentos econômicos regionais (BRASIL. Secretaria de Desenvolvimento Regional, 2012).

\section{CONCLUSÕES}

A condição social da população sertaneja é considerada o principal desafio no semiárido devido a sua carência em educação e mais empregos, e também a conservação da caatinga que está entre as menores prioridades de investimento do governo, contudo, as estratégias regionais de conservação do bioma estão atualmente melhores do que no passado.

As periódicas secas observadas na região Nordeste ampliam o drama econômico e social conduzindo ao desemprego, forçando a crise da produção rural e assim colocando em risco a vida dos agricultores rurais e de seus rebanhos.

Porém, o combate à seca é uma ação limitada e ultrapassada, visto que o clima não se combate, sendo difundida atualmente a alternativa da convivência com o semiárido, cultura que dignifica os sertanejos, entretanto, não se pode obrigar os mesmos a conviverem com a miséria, a falta de hospitais, o desemprego e a fome.

Assim políticas públicas permanentes são apropriadas a região semiárida com o objetivo de superar estruturas de desigualdades socioeconômicas, incentivando o desenvolvimento regional através da geração de empregos, auxílios financeiros e de maior apoio a agricultura, considerando também a continuação dos estudos sobre a convivência harmoniosa com a caatinga e o clima.

As reservas de água devem ser planejadas para mais tempo, dois anos ou mais, também a disponibilidade de plantas forrageiras, que servem para alimento de animais, não podem se esgotar dentro de poucos meses, e a desertificação no semiárido deve ser prevenida e combatida com mais ênfase tanto nas áreas em processo inicial quanto nas reconhecidas como muito graves.

A valorização da caatinga e a sua utilização sustentável são essenciais para solucionar os graves problemas ambientais observados na região semiárida, entretanto, é necessário o reconhecimento e utilização de todo o seu potencial possibilitando a sua conservação e garantindo a qualidade de vida dessa e das demais gerações.

Como o IDHM da região semiárida do Brasil está abaixo da média nacional, ocorre comprometimento dos indicadores sociais o que influencia diretamente oportunidades de crescimento pessoal e profissional como também toda uma gama de serviços e oportunidades. Consequentemente o resultado será uma contínua migração aos espaços socioeconômicos ativos do País, agravando o fenômeno de aglomeração urbana com todas as suas implicações de favelização, pobreza e violência.

Assim, incentivos à agricultura e melhoria dos indicadores sociais, com ênfase para educação, permitirão um aproveitamento maior de parte do potencial produtivo da região 
semiárida brasileira que poderá contribuir para uma maior competitividade do País, gerando emprego, renda e bem estar.

\section{REFERÊNCIAS}

1. $A B^{\prime} S A ́ B E R, A$. Sertões e sertanejos: uma geografia humana sofrida. Revista Eletrônica Estudos Avançados, São Paulo, v. 13, n. 36, p. 7-59, mai./ago. 1999.

2. $A B^{\prime} S A ́ B E R, A$. Os domínios de natureza no Brasil: potencialidades paisagísticas. São Paulo: Ateliê Editorial, 2003.

3. AlbuQUerque, U. P.; ARAÚJO, E. L.; EL-DEIR, A. C. A.; LIMA, A. L. A.; SOUTO, A.; BeZerRA, B. M.; FERRAZ, E. M. N.; FREIRE, E. M. X.; SAMPAIO, E. V. S. B.; LAS-CASAS, F. M. G.; MOURA, G. J. B.; PEREIRA, G. A.; MELO, J. G.; RAMOS, M. A.; RODAL, M. J. N.; SCHIEL, N.; LYRA-NEVES, R. M.; ALVES, R. R. N.; AZEVEDO-JÚNIOR, S. M.; JÚNIOR, W. R. T.; SEVERI, W. Caatinga Revisited: Ecology and Conservation of an Important Seasonal Dry Forest. The Scientific World Journal, Academic Editores, 2012.

4. AMPARO, P. P. Os desafios a uma política nacional de desenvolvimento regional no Brasil. Revista Interações (Campo Grande), v. 15, n. 1, p. 175-192, 2014.

5. ARAÚJO, C. S. F.; SOUSA, A. N. Estudo do processo de desertificação na caatinga: uma proposta de educação ambiental. Revista Ciência \& Educação, Campina Grande, v. 17, n. 4, p. 975-986, 2011.

6. ARAÚJO, M. D. Análise da vegetação de caatinga no Núcleo de Desertificação do Seridó Ocidental da Paraíba: Sítio Água Fria, São José do Sabugi. Monografia da Universidade Estadual da Paraíba, Centro de Ciências e Tecnologia, 2015.

7. ATLAS BRASIL. Atlas do Desenvolvimento Humano no Brasil 2010. Disponível em: < http://www.pnud.org.br/atlas/ranking/Ranking-IDHM-Municipios-2010.aspx > Acesso em: 20 dez. 2013.

8. AZEVEDO, D. C. F. Água: importância e gestão no semiárido nordestino. Revista POLÊMICA, v. 11, n. 1, p. 74-81, 2012.

9. BILAR, A. B. C.; CARVALHO, R. C. O.; GALVÍNCIO, J. D.; DE SOUZA, W. M. Mudanças climáticas e migrações: reflexões acerca dos deslocamentos de nordestinos e haitianos no território brasileiro. Revista Brasileira de Geografia Física, v. 8, n. 6, p. 1673-1691, 2015.

10. BRASIL. 1a. Conferência Nacional de Desenvolvimento Regional. Documento de referência. Brasília: Secretaria de Desenvolvimento Regional/MI, 2012. 28p.

11. BRASIL - Ministério da Educação e do Desporto. Secretaria de Educação Fundamental. Parâmetros curriculares nacionais: meio ambiente e educação. Brasília: SEF, 1998. Disponível em: <http://portal.mec.gov.br/seb/arquivos/pdf/ttransversais.pdf> Acesso em: 26 jan. 2014.

12. BRASIL - Observatório da Seca. Portal Brasil, 2013. Disponível em: <http://www.brasil.gov.br/observatoriodaseca/bolsa-estiagem.html> Acesso em: 29 dez. 2013.

13. BRASIL - Ministério da Integração Nacional. Secretaria de Desenvolvimento Regional Documento de Referência. $2012 . \quad$ Disponível em: <http://www.integracao.gov.br/c/document_library/get_file?uuid=54bce099-503a-4076- 
8613-d90dd6107c79\&groupld=10157> Acesso em: 16 fev. 2014.

14. BRASIL - Ministério da Integração Nacional. Dados sobre estiagem no semiárido. 2012.Disponível em: <http://www.integracao.gov.br/c/document_library/get_file?uuid= Of86f3db-8a9a-4abd-9c20-0dc769db0e7e\&groupld=10157> Acesso em: 28 dez. 2013.

15. BRASIL - Ministério do Meio Ambiente. Monitoramento do desmatamento nos biomas brasileiros por satélite. Acordo de cooperação técnica MMA/IBAMA. Brasília, 2011. Disponível em: < www.mma.gov.br > Acesso em: 03 jan. 2013.

16. BRASIL - Ministério do Meio Ambiente. Sustentabilidade e Repartição dos Benefícios da Biodiversidade. Elaboração de estratégia para captação de recursos para a conservação sustentável do Bioma Caatinga. Secretaria de Biodiversidade e florestas, 2008. Disponível em: <http://www.mma.gov.br/estruturas/203/_arquivos/caatinga_sintesecedraz_203.pdf> Acesso em: 08 mar. 2014.

17. BRASIL - Presidência da Republica. LEI № 9.394 de 20 de dezembro de 1996. Brasília, 1996. Disponível em: <http://www.planalto.gov.br/ccivil_03/leis/19394.htm> Acesso em: 22 jan. 2014.

18. BRASILEIRO, R. S. Alternativas de desenvolvimento sustentável no semiárido nordestino: da degradação à conservação. Revista Scientia Plena, v. 5, n. 5, p. 1-12, 2009.

19. BAPTISTA, N.Q.; CAMPOS, C.H. A convivência com o Semiárido e suas potencialidades. In: CONTI, I.L.; SCHROEDER, E.O. (Organizadores). Convivência com o Semiárido Brasileiro: Autonomia e Protagonismo Social. Fundação de Apoio a Universidade Federal do Rio Grande do Sul, Instituto Ambiental Brasil Sustentável, Agência Espanhola de Cooperação Internacional para o Desenvolvimento, Ministério do Desenvolvimento Social e Combate a Fome, Brasília, 2013.

20. CIRILO, J. A. Políticas públicas de recursos hídricos para o semi-árido. Revista Estudos Avançados, São Paulo, v. 22, n. 63, p. 61-82, 2008.

21. DURKHEIM, E. Educação e Sociologia. Rio de Janeiro/Petrópolis: Editora Vozes, 2011. 132p.

22. FALCÃO, R.C.; FALCÃO, R. M. No meio do Sertão: Experiência da Escola Bom Jesus dos Passos com a metodologia da Educação Contextualizada com o semi-árido. Revista Fórum Identidades, v. 4, n. 2, p. 111-120, jul./dez. 2008.

23. FÉLIX, K.K.F; SILVA, R.A.; SOUZA, M.J.J.B.; OLIVEIRA, A.B.B. Práticas Sustentáveis para se Conviver no Semiárido. Anais do II Encontro de Gestão Social do Programa de Gestão Social - GESPET, Mossoró/RN, 2012.

24. FIGUEIREDO, S. G. Quixadá e a implantação do IFCE: contribuições socioeconômicas, culturais e educacionais na perspectiva da comunidade. $149 \mathrm{f}$. Tese (Doutorado em Geografia) - Universidade Estadual Paulista, Instituto de Geociências e Ciências Exatas, Rio Claro - SP, 2012.

25. FREIRE, P. Educação e mudança. Coleção Educação e Comunicação. Rio de Janeiro: Editora Paz e Terra, 2008.

26. GASPAR, L. Patrimônio imaterial de Pernambuco. Fundação Joaquim Nabuco, Recife, 2010. Disponível em: <http://basilio.fundaj.gov.br/pesquisaescolar/>. Acesso em: 04 jan. 2014.

27. HALAL, C. Y. Ecopedagogia: uma nova educação. Revista de Educação, v. 12, n. 14, p. 87-103, 2015. 
28. IPEA - Instituto de Pesquisa Econômica Aplicada. Caracterização do público potencial do Pronaf B na região Nordeste e no Estado de Minas Gerais: uma análise baseada nos dados do Censo Agropecuário 2006. Relatório de Pesquisa Subprojeto 6 do Projeto de Cooperação Técnica IPEA/PGDR 2010/2011. Brasília, 2013.

29. LEAL, I. R.; SILVA, J. M.; TABARELLI, M.; LACHER JR.; T. E. Mudando o curso da conservação da biodiversidade na Caatinga do Nordeste do Brasil. Revista Megadiversidade, v. 1, n. 1, p. 139146, jul. 2005.

30. LUCENA, F. G. Recursos hídricos no território: os conflitos socioambientais por acesso à água no município de São José do Egito, Sertão do Pajeú-PE. Dissertação (Mestrado em Serviço Social)-Universidade Federal de Pernambuco, Recife, 2014.

31. MARINHO, J. C. B.; SILVA, J. A.; FERREIRA, M. Health education as a transversal proposal: an analysis of the national curriculum guidelines and certain teaching conceptions. História, Ciências, Saúde-Manguinhos, v. 22, n. 2, p. 429-444, 2015.

32. OliVeIRA, D. A.; ABReU MOREIRA, P.; MELO JÚNIOR, A. F.; PIMENTA, M. A. S. Potencial da biodiversidade vegetal da Região Norte do Estado de Minas Gerais. Unimontes Científica, v. 8, n. 1, p. 23-34, 2015.

33. PEREIRA, E. S. Educação Contextualizada e Convivência com o Semiárido: lutas, conquistas e desafios. In: CONTI, I.L.; SCHROEDER, E.O. (Organizadores). Convivência com o Semiárido Brasileiro: Autonomia e Protagonismo Social. Fundação de Apoio a Universidade Federal do Rio Grande do Sul, Instituto Ambiental Brasil Sustentável, Agência Espanhola de Cooperação Internacional para o Desenvolvimento, Ministério do Desenvolvimento Social e Combate a Fome, Brasília, 2013.

34. REBOUÇAS, A. C. Água na Região Nordeste: desperdício e escassez. Revista Estudos Avançados, São Paulo, v. 11, n. 29, p. 127-154, 1997.

35. REBOUÇAS, A. C. Uso inteligente da água. Escrituras Editora e Distribuidora de Livros Ltda., 2015.

36. RÊGO, A. H. Os sertões e os desertos: o combate à desertificação. Brasília: Funag, 2012, 204p.

37. RIEGELHAUPT, E. M.; PAREYN, F. G. C.; GARIGLIO, M. A. O manejo florestal como ferramenta para o uso sustentável e conservação da caatinga. In: GARIGLIO, M. A.; SAMPAIO, E. V. S.; CESTARO, L. A.; KAGEYAMA, P. Y. (Organizadores). Uso Sustentável e Conservação dos Recursos Florestais da Caatinga. Brasília: Serviço Florestal Brasileiro, 2010. Disponível em: < www.mma.gov.br > Acesso em: 08. nov. 2013.

38. RODRIGUES, C. A. O. O desafio de garantir acesso à água para todos e as estratégias para dirimir conflitos de usos dos recursos hídricos: um estudo de caso da bacia hidrográfica do rio Parnaíba. Trabalho de Conclusão de Curso (Especialização)-Centro Universitário de Brasília - UniCEUB, Brasília, 2016.

39. SANTOS, C. F.; ALMEIDA, C. M.; BARRETO, M. O. A educação escolar no semiárido brasileiro: crítica ao princípio da convivência e do desenvolvimento sustentável na formação humana. Revista Facevv, Vila Velha, n.6, p.17-30, jan./jun. 2011.

40. SCHACHT, G. L. A presença de formações relictuais de vegetação em apucarana (PR); A formação de araucária (Araucaria angustifolia). Revista GeoAmazônia, v. 2, n. 4, p. 108-121, 2015. 
41. SCHISTEK, H. O Semiárido Brasileiro: uma região mal compreendida. In: CONTI, I.L.; SCHROEDER, E. O. (Organizadores). Convivência com o Semiárido Brasileiro: Autonomia e Protagonismo Social. Fundação de Apoio a Universidade Federal do Rio Grande do Sul, Instituto Ambiental Brasil Sustentável, Agência Espanhola de Cooperação Internacional para o Desenvolvimento, Ministério do Desenvolvimento Social e Combate a Fome, Brasília, 2013.

42. SILVA, R. M. A. Entre dois paradigmas: combate à seca e convivência com o semi-árido. Revista Sociedade e Estado, Brasília, v.18, n.1/2, p. 361-385, jan./dez. 2003.

43. SILVA, R. M. A. Entre o combate à seca e a convivência com o semi-árido: políticas públicas e transição paradigmática. Revista Econômica do Nordeste, Fortaleza, v. 38, n. 3, jul./set., p. 466-485, 2007.

44. SOUZA, I. P. F. Educação Contextualizada no Semiárido Brasileiro: questões pouco evidenciadas. Revista Educação no Semiárido, p.1-15, 2010.

45. SOUZA, B. I. D.; ARTIGAS, R. C.; LIMA, E. R. V. D. The Caatinga and desertification. Mercator (Fortaleza), v. 14, n. 1, p. 131-150, 2015.

46. SOUSA, M. L. M.; NASCIMENTO, F. R. Estudos geoambientais de bacias hidrográficas em áreas suscetíveis à desertificação no Nordeste do Brasil. Cuadernos de Geografia: Revista Colombiana de Geografia, v. 24, n. 1, p. 13-27, 2015.

47. VASCONCELOS, G. O. S. Educação em Agroecologia: questões para convivência com o semiárido. Cadernos de Agroecologia, v. 8, n. 2, p. 1-4, nov. 2013. 